\title{
BMJ Open Knowledge level and motivation of Hong Kong young adults towards blood donation: a cross-sectional survey
}

\author{
Lorna Kwai Ping Suen, ${ }^{1}$ Judy Yuen-man Siu (D) , ${ }^{2}$ Yik Mun Lee, ${ }^{3}$ \\ Engle Angela Chan ${ }^{1}$
}

To cite: Suen LKP, Siu JY, Lee YM, et al. Knowledge level and motivation of Hong Kong young adults towards blood donation: a crosssectional survey. BMJ Open 2020;10:e031865. doi:10.1136/ bmjopen-2019-031865

- Prepublication history and additional material for this paper are available online. To view these files, please visit the journal online (http://dx.doi. org/10.1136/bmjopen-2019031865).

Received 22 May 2019

Revised 12 December 2019

Accepted 18 December 2019

A) Check for updates

(C) Author(s) (or their employer(s)) 2020. Re-use permitted under CC BY-NC. No commercial re-use. See rights and permissions. Published by BMJ.

${ }^{1}$ School of Nursing, Faculty of Health and Social Sciences, The Hong Kong Polytechnic University, Hung Hom, Hong Kong

${ }^{2}$ Department of Applied Social Sciences, Faculty of Health and Social Sciences, The Hong Kong Polytechnic University, Hung Hom, Hong Kong

${ }^{3}$ Hong Kong Red Cross Blood Transfusion Service, Hospital Authority, King's Park, Hong Kong

Correspondence to Dr Judy Yuen-man Siu; judy.ym.siu@polyu.edu.hk

\section{ABSTRACT}

Objectives This study aimed to (1) determine the knowledge level of young adults towards blood donation, and (2) to understand their donor identity and the meanings of blood donation to them.

Design A questionnaire-based cross-sectional survey. Setting and participants Undergraduate students of a university in Hong Kong recruited by convenience sampling, at public facilities in campus such as student canteens and the Campus Blood Donor Centre of the university.

Outcome measures The questionnaire which consisted of three parts was used for data collection. Part 1 collected sociodemographic information and items associated with blood donation; part 2 related to knowledge on blood donation and part 3 focused on blood donor identity. Univariate and multivariate logistic regression analyses were conducted to determine the $\mathrm{OR}$ and identify the predictors for blood donation.

Results Among the 542 respondents, 274 were nonblood donors and 268 were blood donors. Blood donors generally have a better knowledge towards blood donation than non-blood donors. The results of univariate analyses indicated that being a female $(\mathrm{OR}=1.99, \mathrm{p}<0.001)$, aged 22 years or above $(0 R=234, p<0.001)$, studying at year 4 or $5(0 R=2.12, p=0.003)$, studying health-related programmes $(\mathrm{OR}=1.96, \mathrm{p}<0.001)$, being registered as an organ donor $(\mathrm{OR}=6.59, \mathrm{p}<0.001)$, had prior experience of receiving blood $(0 R=7.60, p<0.001)$ or prior experience of being refused for blood donation $(0 R=5.14, p<0.001)$ were significantly associated with being a blood donor. Having prior experience of receiving blood was the strongest predictor for being a blood donor, followed by being registered as an organ donor, after controlling for all other factors in the logistic regression model.

Conclusions The findings are consistent with selfdetermination theory, which hypothesises that people are more likely to abide with blood donation behaviours that are internally rather than externally motivated.

\section{INTRODUCTION}

Blood is an essential component of human beings that has no alternative source except from humans. ${ }^{1}$ Blood transfusion became a standard procedure in many life-saving situations, such as surgical procedures, burns, blood diseases, haemorrhages or

\section{Strengths and limitations of this study}

This study facilitates our understanding of one's motivations which determine the patterns of behaviour related to blood donation.

- This survey was conducted in one university using convenience sampling method, and thus limits the generalisability of the findings.

- Barriers of giving donation such as personal reasons, psychosocial determinants and cultural factors, that may interlock together and influence donor behaviour, were not investigated.

transplantations. ${ }^{1}{ }^{2}$ Therefore, ensuring a robust supply of safe and accessible blood products is highly important. However, many countries are facing blood shortage. As a not-for-profit organisation, Red Cross has frequently prompted an urgent call for blood donations. ${ }^{3}$ In China, inadequacy of blood supply in many large cities, such as Beijing, Shanghai and Guangzhou, results in deferment or cancellation of surgeries. ${ }^{2}$ Similar to other countries, Hong Kong also encounters significant challenges in maintaining a stable blood supply. In Hong Kong, the Hong Kong Red Cross Blood Transfusion Service (BTS) is the only public institution providing blood to all public and private hospitals. It has been managed by the Hospital Authority since December 1991. ${ }^{4}$ The supply of blood relies entirely on voluntary and non-remunerated blood donors. ${ }^{4}$ Although the number of blood donations was in an increasing trend, the total number of blood donors has been decreasing since 2016. In 2018, the total number of blood donors has dropped to 142 205, which accounted for $2.7 \%$ of the total population. ${ }^{4}$ Only $13.2 \%$ were new blood donors in 2018 , and repeated donors are the major contributors of blood donation in Hong Kong. ${ }^{4}$ According to the BTS, 1100 blood donors are required each day to ensure sufficient supply of blood for clinical use. ${ }^{4}$ However, 
such target is hardly achieved and ends up with frequent appeals for blood by BTS. ${ }^{5}$ In Hong Kong, people who are aged between 16 and 66 years and whose weights are $41 \mathrm{~kg}$ and above, with good health condition are eligible to become blood donors. ${ }^{4}$ For older adult donors, they can donate blood up to 76th birthday provided if they have good health and obtain approval from BTS medical officer. ${ }^{4}$ Young persons aged 16-17 years are required to have parental consent at their first donation. ${ }^{4}$ Those who have a low haemoglobin level, who are on medication and medical follow-up, who have received vaccination just before donation and who are susceptible of infectious diseases are to be deferred from having blood donation. ${ }^{4}$ Due to the blood shortage in Hong Kong, an ageing population with increasing number of older adults, who more likely require blood transfusion, is giving less blood. ${ }^{6}$

Recruitment and retention of young people as blood donors is therefore becoming increasingly important to guarantee the supply of blood products for the healthcare services. ${ }^{7}$ However, only around $10 \%$ of blood donors in Hong Kong are young people aged 16-20 years in 2018. ${ }^{4}$ A survey on knowledge, attitude and practice about blood donation among 841 continuing medical education students conducted in China found that students with more positive attitude towards donation and more basic knowledge about donation are more likely to donate blood. ${ }^{2}$ In recent years, donor identity has been shown to be positively correlated with donation retention. Donor identity, identified by self-determination theory, has been internalised as part of one's self that is positively related to donation intention and future donation behaviour. ${ }^{89}$ The Blood Donor Identity Survey, for example, provides a reliable and valid measure that conceptualises motivation on a continuum of self-determination. ${ }^{10}$ Specially, self-determination theory conceptualises motivation on a continuum of self-determination that includes: (1) amotivation, in which the person has no intention of engaging in the behaviour; (2) external motivation, in which the person is motivated mainly by external forces (such as awards, or to avoid guilt or shame if not donating blood) and (3) internal motivation, in which the person is increasingly motivated by internal forces (eg, donating blood is very important for the health of others; donating blood is consistent with one's overall life goals or to enjoy the blood donation experience) ${ }^{8}$ In a separate study which was conducted in Australia involving 458 eligible donors, the authors concluded that amotivation has a negative direct effect on intention; external regulation has no overall effect on intention, introjected regulation has positive effects on intention and autonomous (internal) motivation can predict intention via attitudes, subjective norms and perceived behavioural control. ${ }^{9}$

\section{Significance of the study}

People are more likely to give blood if donating blood is an important part of their self-identity. ${ }^{11}$ Therefore, the present study determined the knowledge level of young adults towards blood donation, as well as to understand their donor identity and the meanings of blood donation to them. This can help to increase blood donation from young people. Understanding the knowledge level and identity of blood donation among young persons can assist in identifying appropriate strategies to increase their motivation to donate blood. As young people are assumed to be one of the most important potential pools of blood donors, therefore, with this information about how young adults perceive the meanings of blood donation, this can help to recruit young donors in long-term, which can help to stabilise the blood supply in the long run.

\section{METHODS}

\section{Settings and participants}

A total of 542 respondents from a university in Hong Kong were recruited by convenience sampling, at public facilities in campus such as student canteens and the Campus Blood Donor Centre of the university. Data were collected from April to December 2018. Sample size depends on three major factors of descriptive survey: (1) population size, (2) the permissible error of \pm 0.04 and associated confidence level and (3) population proportion of 0.05 to be estimated. ${ }^{12}$ Undergraduate students (full-time and part-time) and who were aged 18-30 years were recruited. The respondents were approached by a research assistant in campus public facilities and were asked to provide written consent to participate in the study.

\section{Instrument}

The questionnaire was self-administered and consisted of three parts. Pilot testing of the questionnaire on 10 university students was conducted to ensure the feasibility of the procedure and the readability of the items for targeted respondents. The different parts of the questionnaire are described as follows:

\section{Part 1: sociodemographic information and items associated with blood donation}

Items included age, gender, year of study, programme, religion, self-reported health status on a scale of $0-10$, employment status and items associated with blood donation (eg, blood donation experiences, whether the respondent is a registrant of organ donation, prior experience of receiving blood and prior experience of being refused for blood donation). Respondents were classified as blood donors if they have donated blood once only, being a repeated donor (ie, have donated blood more than once but does not consider themselves as having a regular habit of donation) or as a regular donor (ie, have donated blood more than once and consider themselves as having a regular habit of donation).

\section{Part 2: knowledge questionnaire on blood donation (12 items)}

The knowledge questionnaire on blood donation was constructed based on an intensive literature review on common myths and fallacies of blood donation, ${ }^{13} 14$ 
with modification and indigenisation to suit the local cultural context. It consists of 12 items and requires true or false responses. The score ranged from 0 to 12, where a higher score indicates better knowledge level towards blood donation. The questionnaire was sent to a panel of five experts to determine if the relevant contents were covered by the instrument. The experts specialise in haematology and/or blood transfusion services (including two academic staff, one Department Operations Manager, one Advanced Practice Nurse and one doctor) and were invited to review the validity of the questionnaire. An excellent content validity index of $95.0 \%$ was achieved. Test-retest reliability was performed on 20 participants at a 2-week interval. The value for intraclass correlation coefficient (single measure) of the knowledge questionnaire was 0.914 (95\% CI $=0.754$ to $0.912, \mathrm{p}<0.001)$, which is well above the targeted value of 0.75 .15

\section{Part 3: Blood Donor Identity Survey (18 items)}

The Blood Donor Identity Survey is a validated questionnaire established by France $e t a l .^{10}$ This questionnaire is a psychometrically sound, multidimensional measure that was adopted in this study to measure one's motivations for blood donation. The scale addresses three different types of motivation underpinned by six motivational factors identified by self-determination theory. The three types of motivation include: (1) amotivation; (2) external motivation (external regulation+introjected regulation) and (3) internal motivation (identified regulation+integrated regulation+intrinsic regulation), for the purpose of determining the patterns of behaviour related to blood donation. Specially, 'amotivation' implies that the person has no intention of engaging in the behaviour; 'external regulation' relates to behaviours that are performed to achieve external rewards; 'introjected regulation' includes behaviour engaged in to avoid guilt or enhance one's ego; 'identified regulation' refers to viewing the behaviour as personally important and valuable; 'integrated regulation' viewed the behaviour as important, and is seen as an important part of one's overall life goals and 'intrinsic regulation' indicates that one enjoy donating blood, and being a blood donor means more than just donating blood. ${ }^{10}$ The motivation subscales demonstrated acceptable to excellent levels of internal consistency, with an average Cronhach's $\alpha$ of 0.70 for both amotivation and external motivation; and 0.90 for internal motivation. ${ }^{8}$ The scale consists of 18 items, responses on a 7-point Likert scale ranging from 1 (not at all true) to 7 (very true). With the consensus of the original authors, the questionnaire was translated into Hong Kong Chinese version. The translated questionnaire was sent to the above expert panel specialising in haematology and/or blood transfusion services to evaluate the translation equivalence, which has an index of $93.3 \%$. The instrument is displayed in online supplementary appendix 1.

\section{Ethics approval}

The study was conducted according to the principles expressed in the Declaration of Helsinki. Participation in this survey was voluntary, and verbal consent was obtained from each of the participants. The confidentiality of the data was strictly observed. Participants were fully aware of the purpose of the study before proceeding with the survey. The institutional review board of our university approved the form of consent indicated by completing the survey.

\section{Patient and public involvement}

There was no patient or public involvement in the study design.

\section{Data analyses}

Descriptive statistics for sociodemographic characteristics and knowledge level towards blood donation of the respondents were presented. The association between categorical variables was examined using $\chi^{2}$ test or Fisher's exact test, where appropriate. Univariate and multivariate logistic regression analyses were conducted to determine the OR and identify the predictors for blood donation. Backward stepwise logistic regression (using $p<0.05$ for entry and $p>0.10$ for removal) was performed to assess a number of variables, which can predict the likelihood of being a blood donor. SPSS V.25.0 (IBM, USA) was used for all statistical analyses. All statistical tests were two-sided, in which a $\mathrm{p}$ value of $<0.05$ was considered statistically significant.

\section{RESULTS}

A total of 542 respondents from a university in Hong Kong were recruited. Among the respondents, 274 were non-blood donors and 268 were blood donors. For the blood donors, 98 had donated blood once only, 110 were repeated donors and 60 were classified as regular donors.

\section{Sociodemographic characteristics and univariate analyses}

Among the 542 respondents, more females than males were blood donors $(63.1 \%$ vs $36.9 \%)$. Majority of them were aged 18-21 years $(79.0 \%)$, had no religion $(76.8 \%)$ and worked part time $(66.1 \%)$. The results of univariate logistic regression indicated that being a female $(\mathrm{OR}=1.99,95 \% \mathrm{CI}=1.41$ to $2.80, \mathrm{p}<0.001)$, aged 22 years or above $(\mathrm{OR}=234,95 \% \mathrm{CI}=1.45$ to $3.77, \mathrm{p}<0.001)$, studying at year 4 or $5(\mathrm{OR}=2.12,95 \% \mathrm{CI}=1.30$ to 3.45 , $\mathrm{p}=0.003)$, studying health-related programmes $(\mathrm{OR}=1.96$, $95 \% \mathrm{CI}=1.37$ to $2.81, \mathrm{p}<0.001)$, being registered as an organ donor $(\mathrm{OR}=6.59,95 \% \mathrm{CI}=3.61$ to $12.02, \mathrm{p}<0.001)$, had prior experience of receiving blood ( $\mathrm{OR}=7.60,95 \%$ $\mathrm{CI}=4.02$ to $14.40, \mathrm{p}<0.001)$ or prior experience of being refused for blood donation $(\mathrm{OR}=5.14,95 \% \mathrm{CI}=2.97$ to $8.89, \mathrm{p}<0.001)$ were significantly associated with being a blood donor (table 1).

\section{Knowledge level towards blood donation}

A higher percentage of blood donors than non-blood donors answered correctly to majority of the items, with 
Table 1 Univariate relationship between sociodemographic and blood donation associated factors on the blood donation status of the respondents $(n=542)$

\begin{tabular}{|c|c|c|c|c|c|c|}
\hline Variable & Total $(n=542)$ & $\begin{array}{l}\text { Non-blood donor } \\
(n=274) \%\end{array}$ & $\begin{array}{l}\text { Blood donor } \\
(n=268) \% \dagger\end{array}$ & $\begin{array}{l}\text { Univariate } \\
\text { OR }\end{array}$ & $95 \% \mathrm{Cl}$ & $\begin{array}{l}P \text { value of } \\
\text { Wald statistic }\end{array}$ \\
\hline \multicolumn{7}{|l|}{ Gender } \\
\hline Male & 45.2 & 53.7 & 36.9 & 1 & & \\
\hline Female & 54.8 & 46.3 & 63.1 & 1.99 & 1.41 to 2.80 & $<0.001^{\star \star \star}$ \\
\hline \multicolumn{7}{|l|}{ Age (years) } \\
\hline $18-19$ & 34.9 & 40.7 & 29.2 & 1 & & \\
\hline $20-21$ & 44.1 & 43.7 & 44.5 & 1.42 & 0.97 to 2.09 & 0.073 \\
\hline 22 or above & 21 & 15.7 & 26.3 & 2.34 & 1.45 to 3.77 & $<0.001^{\star * *}$ \\
\hline \multicolumn{7}{|l|}{ Study year } \\
\hline 1 & 28 & 33.2 & 23 & 1 & & \\
\hline 2 & 24 & 23.1 & 24.8 & 1.55 & 0.97 to 2.48 & 0.069 \\
\hline 3 & 25.8 & 25.7 & 25.9 & 1.45 & 0.92 to 2.31 & 0.113 \\
\hline 4 and 5 & 22.1 & 17.9 & 26.3 & 2.12 & 1.30 to 3.45 & $0.003^{\star \star}$ \\
\hline \multicolumn{7}{|l|}{ Faculty } \\
\hline Not health-related & 65.1 & 72.8 & 57.7 & 1 & & \\
\hline Health-related & 34.9 & 27.2 & 42.3 & 1.96 & 1.37 to 2.81 & $<0.001^{\star * *}$ \\
\hline \multicolumn{7}{|c|}{ Being registered as an organ donor } \\
\hline No & 83.9 & 94.8 & 73.4 & 1 & & \\
\hline Yes & 16.1 & 5.2 & 26.6 & 6.59 & 3.61 to 12.02 & $<0.001^{\star \star *}$ \\
\hline \multicolumn{7}{|c|}{ Know someone who have ever received blood } \\
\hline No & 50 & 44.8 & 55.1 & 1 & & \\
\hline Yes & 50 & 55.2 & 44.9 & 0.66 & 0.47 to 0.93 & $0.016^{*}$ \\
\hline \multicolumn{7}{|c|}{ Prior experience of receiving blood } \\
\hline No & 84.5 & 95.5 & 73.7 & 1 & & \\
\hline Yes & 15.1 & 4.5 & 26.3 & 7.6 & 4.02 to 14.40 & $<0.001^{\star \star \star}$ \\
\hline \multicolumn{7}{|c|}{ Prior experience of being refused for blood donation } \\
\hline No & 83 & 93.3 & 73 & 1 & & \\
\hline \multirow[t]{2}{*}{ Yes } & 17 & 6.7 & 27 & 5.14 & 2.97 to 8.89 & $<0.001^{\star \star \star}$ \\
\hline & $\begin{array}{l}\text { Mean } \\
\text { (SD) }\end{array}$ & & & $\begin{array}{l}\text { Univariate } \\
\text { OR }\end{array}$ & $95 \% \mathrm{Cl}$ & $\begin{array}{l}\text { Test statistics } \\
\text { and } p \text { value } \neq\end{array}$ \\
\hline $\begin{array}{l}\text { Self-reported health } \\
\text { status }(0-100)\end{array}$ & $68.45(15.11)$ & $67.53(15.27)$ & $69.34(14.93)$ & 1.01 & 1.00 to 1.02 & $\begin{array}{l}t=-1.392, \\
p=0.165\end{array}$ \\
\hline
\end{tabular}

${ }^{*} \mathrm{P}<0.05,{ }^{* *} \mathrm{p}<0.01,{ }^{* \star *} \mathrm{p}<0.001$.

†Includes once-only blood donor, repeated blood donor and regular blood donor. †Independent t-test.

a mean total knowledge score of 9.87 and 9.45 , respectively. Many respondents $(61.7 \%)$ did not know that breastfeeding woman cannot donate blood, or woman during menstrual period is not a contraindication of blood donation ( $50.8 \%$ answered incorrectly). In addition, better knowledge towards blood donation was positively associated with taking the action for blood donation, with every 1 score increase in knowledge, it corresponds with 1.12 times of being more likely to be a blood donor (table 2).

\section{Multivariate analyses}

The final model which contained five independent variables (ie, being a registrant for organ donation, had prior experience of receiving blood, amotivation score, external motivation score and internal motivation score) were statistically significant $\left(\chi^{2}=240.95, \mathrm{df}=5, \mathrm{p}<0.001\right)$, indicating that the model was able to distinguish between respondents who were/were not a blood donor. The result of the Hosmer-Lemeshow test indicated that the model effectively fitted the data $(p=0.496)$. The model 
Table 2 Knowledge level of respondents towards blood donation

\begin{tabular}{|c|c|c|c|c|c|}
\hline & Items & $\begin{array}{l}\text { Total } \\
(n=542) \\
\%\end{array}$ & $\begin{array}{l}\text { Non- } \\
\text { blood } \\
\text { donor \% }\end{array}$ & $\begin{array}{l}\text { Blood } \\
\text { donort \% }\end{array}$ & $\begin{array}{l}\text { Test statistics and } \\
\text { p value }\end{array}$ \\
\hline \multicolumn{6}{|c|}{$\begin{array}{l}\text { All donated blood being tested for the presence of HIV } \\
\text { antibodies }\end{array}$} \\
\hline & No & 12.2 & 13.1 & 11.3 & $0.534^{*}$ \\
\hline & Yesł & 87.8 & 86.9 & 88.7 & \\
\hline
\end{tabular}

2 Person under 16 years can donate blood

$\begin{array}{lllll}\text { Noł } & 77.5 & 72 & 82.8 & 0.003 \S^{* *} \\ \text { Yes } & 22.5 & 28 & 17.2 & \end{array}$

3 Pregnant woman can donate blood

$\begin{array}{lllll}\text { Noł } & 78.2 & 77.6 & 78.8 & 0.731 \S \\ \text { Yes } & 21.8 & 22.4 & 21.2 & \end{array}$

4 All people with diabetes or hypertension can donate blood

$\begin{array}{rrrrr}\text { Noł } & 93.4 & 91.8 & 94.9 & 0.147 \S \\ \text { Yes } & 6.6 & 8.2 & 5.1 & \end{array}$

5 All patients with cancer with the risk of metastasis can donate blood

$\begin{array}{rrrrr}\text { Noł } & 92.3 & 90.7 & 93.8 & 0.174 \S \\ \text { Yes } & 7.7 & 9.3 & 6.2 & \end{array}$

6 Woman with menstruation can donate blood

$\begin{array}{lllll}\text { No } & 50.8 & 54.5 & 47.3 & 0.093 \S \\ \text { Yesł } 49.2 & 45.5 & 52.7 & \end{array}$

7 There is an age limit for blood donation

$\begin{array}{lrrrr}\text { No } & 9.4 & 7.8 & 10.9 & 0.215 \S \\ \text { Yes } & 90.6 & 92.2 & 89.1 & \end{array}$

8 Breastfeeding woman can donate blood

$\begin{array}{lllll}\text { Noł } & 38.3 & 35.8 & 40.7 & 0.247 \S \\ \text { Yes } & 61.7 & 64.2 & 59.3 & \end{array}$

9 It is necessary for the donated blood be used within 24 hours

$\begin{array}{rrrrr}\text { Noł } & 95.2 & 93.7 & 96.7 & 0.096 \S \\ \text { Yes } & 4.8 & 6.3 & 3.3 & \end{array}$

10 Hepatitis B carriers can donate blood

$\begin{array}{lrrrr}\text { Noł } & 98.2 & 97.8 & 98.5 & 0.5419 \\ \text { Yes } & 1.8 & 2.2 & 1.5 & \end{array}$

11 Person having fever on the day of donation can still donate blood

$\begin{array}{rrrrr}\text { Noł } & 93.7 & 89.6 & 97.8 & <0.001 \S^{\star * *} \\ \text { Yes } & 6.3 & 10.4 & 2.2 & \end{array}$

12 Smoker can donate blood

$\begin{array}{llll}\text { No } & 27.7 & 28.4 & 27\end{array}$

Yesł $72.3 \quad 71.6 \quad 73$

\begin{tabular}{lllll}
\hline & \multicolumn{2}{l}{ Mean (SD) } & & \multicolumn{1}{l}{$\begin{array}{l}\text { Test statistics and } \\
\text { p value }\end{array}$} \\
\hline $\begin{array}{l}\text { Total } \\
\text { knowledge }\end{array}$ & 9.66 & 9.45 & 9.87 & $\mathrm{t}=-3.7266^{* *}$ \\
score & $(1.330)$ & $(1.404)$ & $(1.220)$ & $\begin{array}{l}\text { p } \leq 0.001^{* *} \\
\end{array}$ \\
& & & & OR: 1.12 \\
& & & $95 \%$ Cl: 1.12 to 1.46 \\
\hline
\end{tabular}

Continued
Table 2 Continued

Mean (SD)

Test statistics and

p value v* $^{*}$

${ }^{\star} \mathrm{P}<0.05,{ }^{* \star} \mathrm{p}<0.01,{ }^{\star \star *} \mathrm{p}<0.001$

†Includes once-only blood donor, repeated blood donor and regular blood donor.

$\ddagger$ Correct answer.

§Chi-square test.

IFisher's exact test.

${ }^{* *}$ Independent t-test.

as a whole explained between $36.0 \%$ (Cox and Snell $\mathrm{R}$ square) and $48.0 \%$ (Nagelkerke $\mathrm{R}$ squared) of the variance in blood donation status, and correctly classified $78.5 \%$ of cases. As shown in table 3, the strongest predictor for being a blood donor was having prior experience of receiving blood $(\mathrm{OR}=15.85,95 \% \mathrm{CI}=7.18$ to $34.99, \mathrm{p}<0.001$ ), followed by being registered as an organ donor $(\mathrm{OR}=4.84,95 \% \mathrm{CI}=2.40$ to $9.78, \mathrm{p}<0.001)$, after controlling for all other factors in the model. The ORs of amotivation and external motivation were $0.70(95 \%$ $\mathrm{CI}=0.63$ to $0.77, \mathrm{p}<0.001)$ and $0.96(95 \% \mathrm{CI}=0.91$ to 1.00 , $\mathrm{p}<0.001$ ), respectively, indicating that for every 1 score increase in amotivation or external motivation indicated a 0.70 times or 0.96 less likely to be a blood donor. Whereas the OR of internal motivation $1.04(95 \% \mathrm{CI}=1.00$ to 1.09 , $\mathrm{p}=0.044$ ) implies that for every 1 score increase in this variable would indicate a 1.04 times more likely to be a blood donor, controlling for other factors in the model.

\section{DISCUSSION}

\section{Summary of study findings}

The findings of this study indicate that blood donors generally have a better knowledge towards blood donation than non-blood donors. Higher knowledge towards blood donation was positively associated with the blood donation action. The results of univariate analyses indicated that being a female, aged 22 years or above, studying at year 4 or 5 , studying health-related programmes, being registered as an organ donor, had prior experience of receiving blood or prior experience of being refused for blood donation were significantly associated with being a blood donor. The findings are consistent with selfdetermination theory, which hypothesises that people are more likely to abide with blood donation behaviours that are internally rather than externally motivated.

\section{Gender disparity in blood donation behaviours}

Gender disparity in blood donation behaviours has been reported, and most studies found that males are positively associated with donation. ${ }^{12}{ }^{216-18}$ For example, men accounts for $70 \%$ of donors in Italy, ${ }^{19}$ and nearly all donors $(99.7 \%)$ surveyed in Nigeria were men. ${ }^{1}$ Male dominance over female blood donors in Nigeria is probably due to cultural beliefs, religious misconceptions, low educational level, poverty and level of civilisation. ${ }^{1}$ Conversely, our study shows that more females than males were blood donors in young adult population, although 


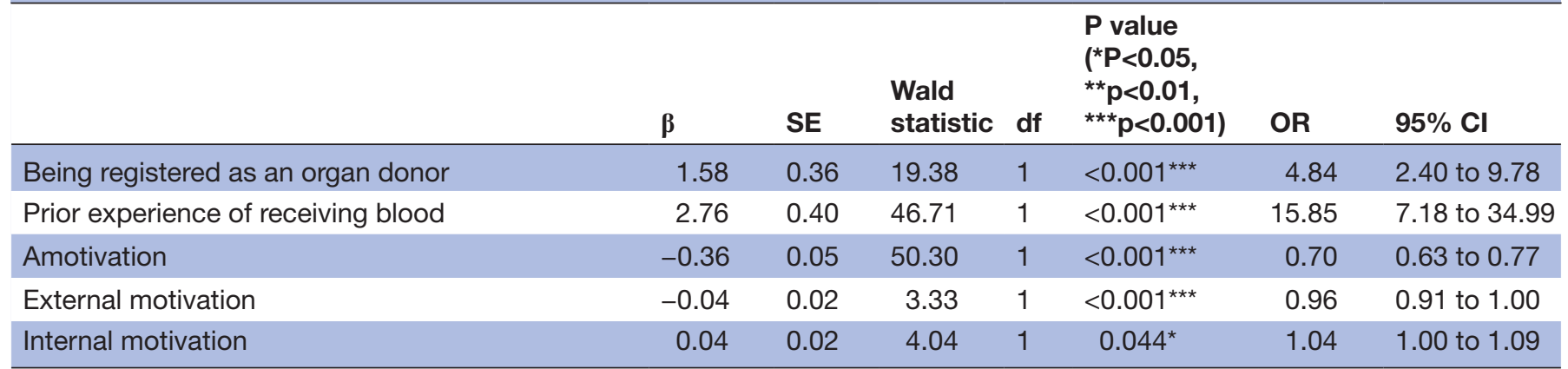

Amotivation: Q1 (I really do not think about donating blood)+Q7 (Blood donation is something I rarely even think about)+Q13 (I really do not have any clear feelings about blood donation). External motivation: Q2 (I donate blood for thank-you gifts)+Q8 (I donate blood for the refreshments)+Q14 (I donate blood to get a donor sticker)+Q3 (I would feel guilty or ashamed of myself if I did not donate blood)+Q9 (I would feel bad about myself if I did not donate blood)+Q15 (I would regret if I did not donate blood) (external regulation=Q2+Q8+Q14; introjected regulation=Q4+Q10+Q16). Internal motivation: Q4 (Donating blood is an important choice I really want to make)+Q10 (Donating blood is very important for the health of others)+Q16 (Blood donation is an important thing to do)+Q11 (Donating blood is consistent with my life goals)+Q17 (Donating blood is very important to me)+Q6 (I enjoy donating blood)+Q12 (For me, being a blood donor means more than just donating blood)+Q18 (Blood donation is an important part of who I am) (identified regulation=Q4+Q10+Q16; integrated regulation $=\mathrm{Q} 5+\mathrm{Q} 11+\mathrm{Q} 17$; intrinsic regulation $=\mathrm{Q} 6+\mathrm{Q} 12+\mathrm{Q} 18)$. (NB: the above items are quoted from France et al. . $^{10}$

the total female blood donation accounted for $46.3 \%$ in Hong Kong in 2018. ${ }^{4}$ Women are more altruistic, and men are more individualistic in terms of motivation to give blood.$^{19}$ A recent systematic review on 28 identified articles concluded that perceived health benefits and incentives are stronger motivators for males than females; and general appeals that focus on altruism are unlikely to be particularly successful in attracting males for blood donation. ${ }^{16}$ On the other hand, male donors are less likely to experience an adverse event while donating, such as vasovagal reactions, fatigue and arm discomfort after donating. ${ }^{16}$ Future studies could be conducted to evaluate specifically the role of gender in the motivation on blood donation. Meanwhile, people aged over 40 years are more likely to be donors. ${ }^{2}$ Due to the sampling criteria, this age group was beyond our recruitment. However, findings in our study also show that those who were relatively older (22 years or above, or at higher years of study) were associated with being a blood donor than the younger group.

\section{Knowledge towards blood donation}

A higher knowledge towards blood donation was also positively associated with the blood donation action. The findings accord with Gao and Wang, ${ }^{2}$ who reported that blood donors are more likely to have more basic knowledge about donation when compared with non-donors. Moreover, people with higher education are more likely to donate blood. Therefore, more efforts in instilling correct concepts on blood donation should start early at a young age.

\section{Conceptualisation of self-determination theory}

Altruism is the most common motivating factor. ${ }^{217}$ The results of this study are consistent with self-determination theory, which hypothesises that people are more likely to abide with blood donation behaviours that are internally versus externally motivated. Our findings indicate that respondents who study health-related programmes were significantly associated with being a blood donor, which may be due to the strong sense of service and altruism, and the attitude of always being ready to put the needs of others over one's self. ${ }^{20}$

Being registered as an organ donor was found to be positively associated with being a blood donor. A descriptive study was conducted in Ireland ${ }^{21}$ to determine whether being a blood donor would be a better predictor to donate urological tissue than being an organ donor card carrier. Results showed that blood donors and organ card carriers are more likely to be willing to donate tissue for research purposes than those who are not, probably due to the sense of medical altruism in the person's identity. ${ }^{21}$ As expected, a person with prior experience of receiving blood would be more willing to be a blood donor in return for the graciousness that they have received from others. Interestingly, there is a higher percentage of people with prior experience of being refused for blood donation among the blood donors than the non-blood donors. Thus, previous rejection experience may not affect one's determination to be a donor when they were eligible.

\section{Barriers and strategies}

The new ' $3+3+4$ ' education system of Hong Kong (ie, 3 years of junior secondary school, 3 years of senior secondary school and 4 years of university undergraduate education) commenced in 2009 is believed to have a negative impact on blood donations among the young people. This is reflected from a $45 \%$ drop of the total number of blood donation among secondary school students from 2011 to $2016 .{ }^{22}$ Secondary school students have a relatively higher donation rate than undergraduate students in Hong Kong, probably due to the easier arrangement of blood donation sessions in classes in secondary schools than the relatively unstructured timetables of individual 
university students due to elective subjects or special study patterns. Many young people have been urged to donate blood based on external social pressure and may be unwilling to donate again when removed from that environment. ${ }^{17}$ Under the ' $3+3+4$ ' reforms that started in the academic year 2009-2010, standard university degrees increased from 3 to 4 years, thus resulting in the decline in blood donation by young people in recent years. ${ }^{23}$ However, because of the increased study duration of university education, it is suggested for blood donation promotions to put more focus on university students in the future in order to fill up the donation gap given the decreasing donation from secondary school students. Although the education reform has led to the longer education duration in universities and thus an increasing number of university students, the increase of blood donation among university students was just $24 \%$ from 2011 to $2016 .{ }^{22}$ Indeed, in response to the unremarkable increase of blood donation among university students, BTS has implemented strategies to recruit potential donors from universities, such as by establishing campus blood donor centres in two universities of Hong Kong, organising mobile donation service in different universities, and carrying out 'Be cool be a blood donor university programme' as well as 'Young Blood Programme'. These programmes have successfully recruited new blood donors and retained existing donors who are studying in universities.

Apart from encouraging individuals to initiate the first donation, it is important to encourage first-time donors to return for repeat donations. ${ }^{17}$ Previous research documented that young first-time donors have lower return rates and higher deferral rates than older ones. ${ }^{7} 11172425$ Lifestyle-related reasons are common causes to defer blood donation among young prospect donors, whereas prospect donors over 30 years of age are more frequently deferred for health-related reasons. ${ }^{7}$ Given that repeat donors could supply a stable and relatively safe source of blood, ${ }^{25}$ the introduction of effective donor-retention strategies is imperative.

Motivational interview, conducted approximately 3-4 weeks after the most recent donation of the donor, is a potentially useful strategy to enhance retention of existing blood donors, particularly among those who express a greater sense of internal motivation for giving blood. ${ }^{8}$ The interviewer followed a standardised script that encouraged donors to explore intrinsic and extrinsic motivations for giving blood, identify concerns or barriers to future donation and engage in individualised problem solving to address any perceived concerns or barriers. ${ }^{8}$ This strategy is also effective in enhancing donation intention and intrinsic motivation for experienced donors and for non-donors. ${ }^{26}$

The importance of social networks as a recruitment channel for donation has been reported previously. Therefore, young active donors should be encouraged to recruit donors via their social circle, such as friends, fellow students and coworkers. ${ }^{7}$ First-time donors are influenced more by peer pressure and are more concerned about pain, whereas regular donors are more likely to have a concern for others as a motivation to donate blood but considered the waiting time. ${ }^{11}$ Existing strategies of BTS, such as the availability of free Blood Donor App to schedule an appointment, the use of 'RapidPass' to speed up the donation process by doing the predonation reading and answer the health history questionnaire online, ${ }^{3}$ are implemented to cater the needs of the young donors.

\section{Limitations}

This study has some limitations. The Blood Donor Identity Survey facilitates our understanding of one's motivations which determine the patterns of behaviour related to blood donation. However, other possible reasons, such as barriers of donation, personal reasons, psychosocial determinants and social and cultural factors, which may interlock together and influence donor behaviour, are not investigated. To facilitate a better understanding of these potential factors, a qualitative approach should be considered in future studies. This survey is only limited to the undergraduate students from one university using convenience sampling method, and thus large-scale studies with more field sites using random sampling may reflect more representative information and facilitate comparisons of the motivations and barriers among blood donors who have donated blood once only, have repeatedly donated or constantly donated blood.

\section{CONCLUSIONS}

Blood donors generally have a better knowledge towards blood donation than non-blood donors. Having prior experience of receiving blood was the strongest predictor for being a blood donor, followed by being a registrant of organ donation, after controlling for all other factors in the logistic regression model. The findings are consistent with self-determination theory, which hypothesises that people are more likely to abide with blood donation behaviours that are internally rather than externally motivated.

Acknowledgements The authors would like to thank the participants for their sincere support. The authors would also like to thank Ms Siuki Tang for the assistance in the data collection.

Contributors Conceptualisation: JY-MS. Data curation: JY-MS, LKPS, EAC, YML. Formal analysis: LKPS. Funding acquisition: JY-MS. Investigation: JY-MS. Methodology: JY-MS, LKPS, EAC. Project administration: JY-MS. Resources: JY-MS. Supervision: JY-MS, LKPS. Validation: JY-MS, LKPS. Writing —original draft: LKPS. Writing — review and editing: JY-MS, LKPS, EAC, YML.

Funding This work was supported by the General Research Fund, Research Grants Council, University Grants Committee, Hong Kong (grant number 15602018) and the Faculty Collaborative Research Scheme between Social Sciences and Health Sciences, The Hong Kong Polytechnic University (grant number P0001201/ZVKB).

Disclaimer The funders have no role in the study design, data collection, analysis and interpretation, as well as the publication of data.

Competing interests None declared.

Patient consent for publication Not required. 
Ethics approval The protocol of this study was approved by the Ethics Committee of the Department of Applied Social Sciences (HSEARS20160714002), The Hong Kong Polytechnic University.

Provenance and peer review Not commissioned; externally peer reviewed.

Data availability statement Data are available on reasonable request.

Open access This is an open access article distributed in accordance with the Creative Commons Attribution Non Commercial (CC BY-NC 4.0) license, which permits others to distribute, remix, adapt, build upon this work non-commercially, and license their derivative works on different terms, provided the original work is properly cited, appropriate credit is given, any changes made indicated, and the use is non-commercial. See: http://creativecommons.org/licenses/by-nc/4.0/.

ORCID iD

Judy Yuen-man Siu http://orcid.org/0000-0003-0825-6564

\section{REFERENCES}

1 Alla J, Muhammad Y, Habeeb A. Gender distribution of blood donors and blood recipients in Rasheed Shekoni teaching hospital Dutse, Jigawa state, Nigeria. , 2019: 2, 20-4. https://bit.ly/2Xc9lBk

2 Gao L, Wang Q. Survey on knowledge, attitude and practice about blood donation among continuing medical education (CME) students in Sichuan Province, China. Transfus Apher Sci 2017;56:454-8.

3 Wayne F. Red cross blood shortage prompts urgent call for blood donations. Elkhart truth, the (in), 2018. Available: https://bit.ly/ 2XkO8ux

4 Hong Kong Red Cross Blood Tranfusion Service. Available: https://www5.ha.org.hk/rcbts/enarticle.asp?bid=86\&MenulD=3\#. XbA5XqZIKUk

5 Hong Kong Red Cross Blood Transfusion Service. Blood for life. Available: https://www.facebook.com/BloodForLifeHKRCBTS/

6 SCMP Editorial. Hong Kong must be able to count on blood donors. South China Morning Post, 2018. Available: https://bit.ly/2UE7DBs

7 Misje AH, Bosnes V, Heier HE. Recruiting and retaining young people as voluntary blood donors. Vox Sang 2008;94:119-24.

8 France CR, France JL, Carlson BW, et al. A motivational interview promotes retention of blood donors with high internal motivation. Transfusion 2017;57:2433-9.

9 Williams LA, Sun J, Masser B. Integrating self-determination theory and the theory of planned behaviour to predict intention to donate blood. Transfus Med 2019;29:59-64.

10 France CR, Kowalsky JM, France JL, et al. The blood donor identity survey: a multidimensional measure of blood donor motivations. Transfusion 2014;54:2098-105.
11 Giles M, McClenahan Cairns C C, Mallet J. An application of the theory of planned behaviour to blood donation: the importance of self-efficacy. Health Educ Res 2004;19:380-91.

12 Wang MO, Fitzhugh E, Westerfield RC. Determining sample size for simple random surveys. Health Values 1995;19:53-6.

13 Lucindo Zucoloto M, Zangiacomi Martinez E. Development of a questionnaire to assess knowledge regarding blood donation in a Brazilian population. Rev Bras Hematol Hemoter 2016;38:175-7.

14 Papagiannis D, Rachiotis G, Symvoulakis EK, et al. Blood donation knowledge and attitudes among undergraduate health science students: a cross-sectional study. Transfus Apher Sci 2016;54:303-8.

15 Portney LG, Watkins MP. Foundations of clinical research. 3rd edn. New Jersey: Prentice Hall, 2009.

16 Carver A, Chell K, Davison TE, et al. What motivates men to donate blood? A systematic review of the evidence. Vox Sang 2018;113:205-19.

17 Lownik E, Riley E, Konstenius T, et al. Knowledge, attitudes and practices surveys of blood donation in developing countries. Vox Sang 2012;103:64-74.

18 Shashahani H, Yavari MT, Attar M, et al. Knowledge, attitude and practice study about blood donation in the urban population of Yazd, Iran, 2004. Transfus Med 2006;16:403-9.

19 Bani M, Giussani B. Gender differences in giving blood: a review of the literature. Blood Transfus 2010;8:278-87.

20 Pomona College. Characteristics of the successful healthcare professionals, 2019. Available: https://www.pomona.edu/ administration/pre-health/prepare/characteristics

21 McKenzie KD, Fitzpatrick PE, Sheehan JD. Tissue banking: relationship with blood donor and organ donor card status. ISRN Urol 2012;2012:475729.

22 Hong Kong Red Cross Blood Transfusion Service. Fact sheet: blood collection and use. Available: https://www5.ha.org.hk/rcbts/UPFILE/ BookFile/20176269755610.pdf

23 Nip A. Blood donations from schools drop under new system. South China Morning Post, 2013. Available: https://bit.ly/2UjNiMR

24 Schreiber GB, Sharma UK, Wright DJ, et al. First year donation patterns predict long-term commitment for first-time donors. Vox Sang 2005;88:114-21.

25 Masser BM, White KM, Hyde MK, et al. Predicting blood donation intentions and behavior among Australian blood donors: testing an extended theory of planned behavior model. Transfusion 2009;49:320-9.

26 Livitz IE, Fox KR, Himawan LK, et al. A brief motivational interview promotes internal motivation to donate blood among young adults with and without a prior donation history. Transfusion 2017;57:1527-35. 